American Journal of

Hospice and Palliative Medicine

\title{
Usefulness of Palliative prognostic Index for advanced cancer patient in home care setting
}

\begin{tabular}{|r|l|}
\hline Journal: & American Journal of Hospice and Palliative Medicine \\
\hline Manuscript ID: & Draft \\
\hline Manuscript Type: & Medical Manuscripts \\
\hline Keyword: & $\begin{array}{l}\text { Advanced Cancer patient, home care setting, Prognostic prediction, } \\
\text { Palliative Prognostic Index, Retrospective study, Palliative care, } \\
\text { Home visiting service }\end{array}$ \\
\hline
\end{tabular}

\section{SCHOLARONE ${ }^{\text {Th }}$}

Manuscripts 
Usefulness of the Palliative Prognostic Index for advanced cancer patients in the home care setting

\section{Introduction}

Prognostic prediction is necessary for advanced cancer patients, especially those in the home care setting, in order to determine treatment goals, the content and location of provided care, and indications for hospital referral. ${ }^{1)}$ An appropriate prognostic prediction tool is therefore essential not only for patients and their families, but also for the healthcare professionals who support their decision making. ${ }^{2)}$ Previous studies have examined several prognostic prediction tools for cancer patients, for example the Palliative Prognostic Index (PPI), ${ }^{3)}$ Palliative Performance Scale, ${ }^{3)}$ Cancer Prognostic Scale, ${ }^{3)}$ Palliative Prognostic Scale, ${ }^{4)}$ Japan Palliative Oncology Study-Prognostic Index (J-POS-PI), ${ }^{5)}$ and Prognosis in Palliative Care Study model, ${ }^{6)}$ and each was properly validated. These tools are intended for use in assessing inpatient and ambulatory patients, and the appropriateness of their application to advanced cancer patients in the home care setting is uncertain. Only Stone et al. prospectively studied the usefulness of the PPI in 194 cancer patients in a variety of settings: $73.7 \%$ of patients were hospitalized, $25.8 \%$ were in the home care setting, and $0.5 \%$ were in hospice. ${ }^{8)}$

The PPI was defined based on performance status assessment using the Palliative Performance Scale (PPS), oral intake, and the presence or absence of dyspnea, edema, and delirium (Table 1). The PPI does not require blood tests or radiological evaluation, and would therefore be very useful for cancer patients in the home care setting as compared to other validated prognostic prediction tools. Each PPI component is assigned an individual score, and these are added to derive the overall score. The final 
PPI score classifies patients into 1 of 3 groups: those with survival predicted to be shorter than 3 weeks (PPI $\geq 6$ ), shorter than 6 weeks (PPI $\geq 4$ ), or more than 6 weeks $(\mathrm{PPI}<4)$.

The PPI was developed and successfully validated for cancer patients in palliative care units by Morita et al. in Japan, ${ }^{7)}$ but the usefulness of the PPI for advanced cancer patients in the home care setting has not been established. The aims of this study were thus to clarify the sensitivity and specificity of the PPI for this particular population.

\section{Methods}

Our study population included all advanced cancer patients who received home visiting services regularly from Yamato Clinic between April 2007 and June 2009, and who died at home or in the hospital. Yamato Clinic provides ambulatory care and home visiting services for community residents, with 3 doctors specialized in family medicine and palliative care. We assessed the components of the PPI during the first home visit, as is our usual practice. In June 2010, one researcher (JH) then used medical records from patients' first home visits to determine actual survival time as well as each component of the PPI: PPS score, oral intake, and the presence or absence of dyspnea, edema, and delirium. The PPI score was calculated for each patient, along with overall sensitivity and specificity. Survival predictions were defined as mentioned above: less than three weeks for $\mathrm{PPI} \geq 6$, and less than 6 weeks for $\mathrm{PPI} \geq 4$.

This study was conducted in conformity with the Declaration of Helsinki and was carried out with special regard for the protection of individual data.

Results 
Sixty-five patients (41 males) were included in this study. Table 2 shows patient background information in detail. The mean patient age was 73.5 , with 25 patients (38.4\%) in their 70 s and 14 patients $(21.5 \%)$ in their 80 s. The primary cancer site was the stomach/esophagus in 12 patients (18.4\%), the lung in 11 patients (16.9\%), and the colon/rectum/anus in 11 patients $(16.9 \%)$. The mean survival time after the first home visit was 55 days. Survival time was shorter than 3 weeks in 22 patients $(33.8 \%)$ and shorter than 6 weeks in 35 patients $(53.8 \%)$ (Table 2).

Twenty-one patients (32.3\%) had PPI scores $\geq 6$, while 29 (44.6\%) had PPI scores $\geq 4$ (Table 3). The distribution of performance status and clinical symptoms is indicated in Table 4. Twelve patients with PPI scores $\geq 6$ survived for less than 3 weeks, while 22 patients with PPI scores $\geq 4$ survived for less than 6 weeks (Tables 5, 6). Three-week survival was predicted with a sensitivity of $55 \%$ (95\% CI, 33-75), a specificity of $79 \%$ (95\% CI, 66-91), a positive predictive value of 57\%, and a negative predictive value of $77 \%$. Six-week survival was predicted with a sensitivity of $63 \%$ (95\% CI, 46-78), a specificity of $77 \%$ (95\% CI, 61-91), a positive predictive value of $77 \%$, and a negative predictive value of $64 \%$ (Table 7).

\section{Discussion}

The most important finding of this study was that the sensitivity of the PPI for advanced cancer patients in the home care setting was lower than for advanced cancer patients in palliative care units as previously reported. ${ }^{7)}$ To the best of our knowledge, this study is the first to clarify the usefulness of the PPI for advanced cancer patients in the home care setting. It demonstrated the sensitivity and specificity of the PPI as a prognostic prediction tool for 3- and 6-week survival. Our findings suggest limitations of the PPI in 
this population and setting.

One possible reason for the discrepancy in PPI sensitivity between advanced cancer patients in palliative care units and those in the home care setting is the differential prevalence of delirium, which is the most heavily weighted score in the PPI scoring system. In our study, the prevalence of delirium in the home care setting was $9.2 \%$, whereas Morita et al. ${ }^{7)}$ reported a prevalence of $23 \%$ in the hospice setting. This discrepancy suggests 2 possibilities: 1) The prevalence of delirium in the hospice setting may in fact be higher than that in the home care setting, ${ }^{9,10)}$ or 2) we might have underestimated the prevalence of delirium because we diagnosed it only by retrospective chart review.

In addition to the results above, we found the specificity of PPI for advanced cancer patients in the home care setting to be nearly $80 \%$ in our study for both 3- and 6-week survival. These results suggest that the PPI might not be useful as a screening tool for poor prognosis in the home care setting because of its low sensitivity, but might be useful with PPI scores <4, predicting survival longer than 6 weeks, and with PPI scores $<6$, predicting survival longer than 3 weeks.

This study has several limitations. First, it was carried out in one institution and the study population was small, restricting the generalizability of our results. Second, one researcher $(\mathrm{JH})$ was aware of each patient's prognosis before performing the medical chart review, making it impossible to confirm the absence of bias during data collection. However, because the PPI score is defined based on objective indicators, this limitation most likely had only a relatively small effect on the study outcome. Third, since this study was carried out retrospectively, we cannot be certain that patients' symptoms and signs were recorded correctly at the first home visit. 
In conclusion, this study showed that the PPI had a lower sensitivity for advanced cancer patients in the home care setting than for those in palliative care units. Further research is needed to develop more accurate prognostic prediction tools for use in the home care setting.

Declaration of Conflicting Interests: The author(s) declared no conflicts of interest with respect to the authorship and/or publication of this article.

Funding: The author(s) received no financial support for the research and/or authorship of this article. 
Table 1. Palliative Prognostic Index

2 3 4 5 6

$\begin{array}{lr}\text { Severely reduced } & 2.5 \\ \text { Moderately reduced } & 1 \\ \text { Normal } & 0\end{array}$

Present 1

Absent 0

Dyspnea at rest Present 3.5

Absent 0

Delirium $\quad$ Present 4

Absent 0

Overall PPI score was calculated by adding each component score 
Table 2. Patient background information $(n=65)$

\begin{tabular}{|c|c|c|c|}
\hline & & $\mathrm{n}$ & $(\%)$ \\
\hline \multirow[t]{2}{*}{ Gender } & Male & 41 & $(63.0)$ \\
\hline & Female & 24 & $(37.0)$ \\
\hline \multicolumn{2}{|l|}{ Mean age (years) $†$} & 73.5 & $(35-96)$ \\
\hline \multicolumn{2}{|c|}{ Mean survival duration (days) $†$} & 55.0 & $(1-344)$ \\
\hline \multirow[t]{6}{*}{ Age distribution } & $35-49$ & 2 & $(3.1)$ \\
\hline & $50-59$ & 7 & $(10.8)$ \\
\hline & $60-69$ & 11 & $(16.9)$ \\
\hline & $70-79$ & 25 & $(38.4)$ \\
\hline & $80-89$ & 14 & $(21.5)$ \\
\hline & $90-$ & 6 & $(9.2)$ \\
\hline \multirow[t]{11}{*}{ Primary cancer site } & Stomach/Esophagus & 12 & $(18.4)$ \\
\hline & Lung & 11 & $(16.9)$ \\
\hline & Colon/rectum/anus & 11 & $(16.9)$ \\
\hline & Pancreas & 7 & $(10.8)$ \\
\hline & Prostate & 4 & $(6.2)$ \\
\hline & Kidney/bladder & 4 & $(6.2)$ \\
\hline & Liver & 3 & (4.6) \\
\hline & Breast & 3 & (4.6) \\
\hline & Biliary system & 3 & (4.6) \\
\hline & Unknown & 3 & (4.6) \\
\hline & Others & 4 & $(6.2)$ \\
\hline \multirow[t]{10}{*}{ Survival duration } & $0 \leq$ week $<1$ & 11 & (16.9) \\
\hline & $1 \leq$ week $<2$ & 8 & (12.3) \\
\hline & $2 \leq$ week $<3$ & 3 & (4.6) \\
\hline & $3 \leq$ week $<4$ & 7 & (10.8) \\
\hline & $4 \leq$ week $<5$ & 2 & (3.0) \\
\hline & $5 \leq$ week $<6$ & 4 & (6.2) \\
\hline & $6 \leq$ week $<7$ & 7 & 10.8 \\
\hline & $7 \leq$ week $<8$ & 0 & $(0.0)$ \\
\hline & $8 \leq$ week $<9$ & 3 & (4.6) \\
\hline & $9 \leq$ week & 20 & (30.7) \\
\hline
\end{tabular}

† Mean (range) 
Table 3. Distribution of PPI scores $(n=65)$

\begin{tabular}{lrr}
\hline \multicolumn{1}{r}{ score } & $\mathrm{n}$ & $(\%)$ \\
\hline 0 & 3 & $(4.6)$ \\
$1 \leq \mathrm{PPI} \leq 2$ & 4 & $(6.2)$ \\
$\mathrm{PPI}=2.5$ & 6 & $(9.2)$ \\
$3.5 \leq \mathrm{PPI}<4$ & 23 & $(35.4)$ \\
$4 \leq \mathrm{PPI}<6$ & 8 & $(12.3)$ \\
$6 \leq \mathrm{PPI} \leq 8$ & 13 & $(20.0)$ \\
$8.5 \leq \mathrm{PPI} \leq 10$ & 3 & $(4.6)$ \\
$10.5 \leq \mathrm{PPI} \leq 12$ & 5 & $(7.7)$ \\
$\mathrm{PPI} \geq 12.5$ & 0 & $(0.0)$ \\
\hline
\end{tabular}


Table 4. Patient performance status and symptoms $(n=65)$

\begin{tabular}{llrr}
\hline & & $\mathrm{n}$ & $(\%)$ \\
\hline Palliative Performance Scale & $10 \%-20 \%$ & 6 & $(9.2)$ \\
& $30 \%-50 \%$ & 51 & $(78.5)$ \\
& $60 \%$ & 8 & $(12.3)$ \\
& & & \\
Oral intake & Severely reduced & 11 & $(16.9)$ \\
& Moderately reduced & 36 & $(60)$ \\
& Normal & 15 & $(23.1)$ \\
Edema & & & \\
& Present & 22 & $(33.8)$ \\
& Absent & 43 & $(66.2)$ \\
Dyspnea at rest & & & \\
& Present & 14 & $(21.5)$ \\
& Absent & 51 & $(78.5)$ \\
Delirium & & & \\
& Present & 6 & $(9.2)$ \\
& Absent & 59 & $(90.8)$ \\
\hline
\end{tabular}


Table 5. PPI score and 3-week survival

\begin{tabular}{lccc}
\hline & $<3$-week survival & $\geq 3$-week survival & Total \\
\hline $\mathrm{PPI} \geq 6$ & $12 \square$ & 9 & 21 \\
$\mathrm{PPI}<6$ & 10 & 34 & 44 \\
\hline Total & 22 & 43 & 65 \\
& & \\
$\square$ Number of patients surviving $<3$ weeks with PPI scores $>6$ &
\end{tabular}


Table 6. PPI score and 6-week survival

\begin{tabular}{lccc}
\hline & $<6$-week survival & $\geq 6$-week survival & Total \\
\hline $\mathrm{PPI} \geq 4$ & $22 \square$ & 7 & 29 \\
$\mathrm{PPI}<4$ & 13 & 23 & 36 \\
\hline Total & 35 & 30 & 65 \\
& & \\
$\square$ Number of patients surviving $<6$ weeks with PPI scores $>4$ &
\end{tabular}


Table 7. Accuracy of the PPI for advanced cancer patients in the home care setting

\begin{tabular}{ccc}
\hline & $<3$ weeks $(\%)$ & $<6$ weeks $(\%)$ \\
\hline Sensitivity & 54.5 & 62.8 \\
Specificity & 79.0 & 76.6 \\
Positive Predictive Value & 57.1 & 75.8 \\
Negative Predictive Value & 77.2 & 63.8 \\
\hline
\end{tabular}

10
11 
References

1) Glare, P. A., \& Sinclair, C. T. Palliative medicine review: prognostication. Journal of palliative medicine. 2008;11(1), 84-103.

2) Steinhauser, K. E., Christakis, N. A., Clipp, E. C, et al. Preparing for the end of life: preferences of patients, families, physicians, and other care providers. Journal of pain and symptom management. 2001;22(3), 727-37.

3) Lau, F., Cloutier-Fisher, D., Kuziemsky, C., Black, F., Downing, M., Borycki, E., \& Ho, F. A systematic review of prognostic tools for estimating survival time in palliative care. Journal of palliative care. 2007;23(2), 93-112.

4) Glare, P. A., Eychmueller, S., \& McMahon, P. Diagnostic accuracy of the palliative prognostic score in hospitalized patients with advanced cancer. Journal of clinical oncology. 2004;22(23), 4823-8.

5) Hyodo I, Morita T, Adachi I, et al. Development of a predicting tool for survival of terminally ill cancer patients. Japanese journal of clinical oncology. 2010;40(5):442-8. 
6) Gwilliam B, Keeley V, Todd C, et al. Development of Prognosis in Palliative care Study (PiPS) predictor models to improve prognostication in advanced cancer: prospective cohort study. BMJ (Clinical research ed.). 2011;343:d4920.

7) Morita T, Tsunoda J, Inoue S, Chihara S. The Palliative Prognostic Index: a scoring system for survival prediction of terminally ill cancer patients. Support Care Cancer. 1999;7(3):128-133.

8) Stone, C. A., E. Tiernan, et al. Prospective validation of the palliative prognostic index in patients with cancer. J Pain Symptom Manage. 2008:35(6): 617-22

9) Morita $\mathrm{T}$, Akechi T, Ikenaga M, et al. Terminal delirium: recommendations from bereaved families' experiences. Journal of pain and symptom management. 2007;34(6):579-89.

10)Boorsma M, Joling KJ, Frijters DHM, et al. The prevalence, incidence and risk factors for delirium in Dutch nursing homes and residential care homes. International journal of geriatric psychiatry. 2011. 